\title{
SPLIT SKIN GRAFTING IN FOURNIER GANGRENE OF PENIS: A CASE REPORT
}

Nagraj Mitra1, Somshekar Solpure²

\section{HOW TO CITE THIS ARTICLE:}

Nagraj Mitra, Somshekar Solpure. "Split Skin Grafting in Fournier Gangrene of Penis: A Case Report". Journal of Evolution of Medical and Dental Sciences 2014; Vol. 3, Issue 19, May 12; Page: 5210-5214,

DOI: $10.14260 /$ jemds/2014/2576

ABSTRACT: Fournier's gangrene is a rare disease with rapidly progressive necrotizing fasciitis of the genital, perineal and perianal regions and leads to sepsis and death. We report a case of localized Fournier's gangrene of the penis. A 38 -year-old man suffered an abrasion of the penis following a trivial trauma following which he developed pain as well as redness and swelling appeared on the penile surface, he consulted to our hospital, Fournier's gangrene was suspected immediately, we started broad-spectrum antibacterial chemotherapy and performed debridement. The postoperative course was good and then the open wound was closed with partial thickness skin graft. Only few cases of Fournier's gangrene of the penis have been reported. Patient has come for follow up on $2^{\text {nd }}$, $3^{\text {rd }}$ and 6 months and his erectile function preserved.

KEYWORDS: Anaerobes, antibiotics, debridement, Fournier's gangrene, penis, Split skin grafting.

INTRODUCTION: Fournier's gangrene is a necrotizing infection that involves the soft tissues of the male genitalia.1,2 Fournier's gangrene is a specific form of necrotizing fasciitis, a general term introduced in 1951, by Wilson, to describe infection of the soft tissue, which involves the deep and superficial fascia, regardless of the location. Originally, the term Fournier's gangrene was used to describe idiopathic gangrene of the genitalia; however, it has also been used to describe most soft tissue necrotizing infections of the perineum, independent of the cause. Modern day use of the term Fournier's gangrene should be restricted to describe infections that primarily involve the genitalia.

In his presentation, Fournier reviews the systemic and local factors that influence this fulminative process. Local factors related to the trauma of the genitalia accounted for a vast majority of the cases of genital gangrene. Although Fournier has not emphasized the role of diabetes in this article, diabetes was known as the leading predisposing systemic factor. ${ }^{3}$ Fournier describes in anecdotes some of the misconceptions of the times that created this condition, including the practice of nighttime ligation of the prepuce to control enuresis or an attempted birth control technique practiced by an adulterating man to avoid impregnating his married lover. Since Fournier's description, subsequent knowledge has shown that it has an identifiable cause, which frequently manifests in a more indolent fashion. Trauma to the genitalia continues to be a frequently recognized vector for the introduction of bacteria that initiate the infectious process. ${ }^{4}$

CASE REPORT: A 38 years-old-male patient presented with fever and pain, with black discoloration of the penis for four days. There was a history of trivial trauma and there was no any sepsis in the genitoperineal area. On general physical examination, the patient was not febrile, conscious oriented to time place and person.

Local examination revealed black discoloration of the penile skin extending up to the penoscrotal junction without any clear line of demarcation]. There were no other foci of infection in the genitoperineal area. The prostate gland was normal on rectal examination. Routine hematological 


\section{CASE REPORT}

examination revealed leukocytosis and neutrophilia. Urine microscopy revealed no abnormality. Random blood sugar, blood urea, and serum creatinine were within normal limits. The ultrasonological examination of the abdomen and pelvis was normal. Discharge sent for culture showed isolated growth of streptococcus sensitive to cefotaxime, ceftriaxone, amoxicillin/ clauvulanic acid and amikacin.

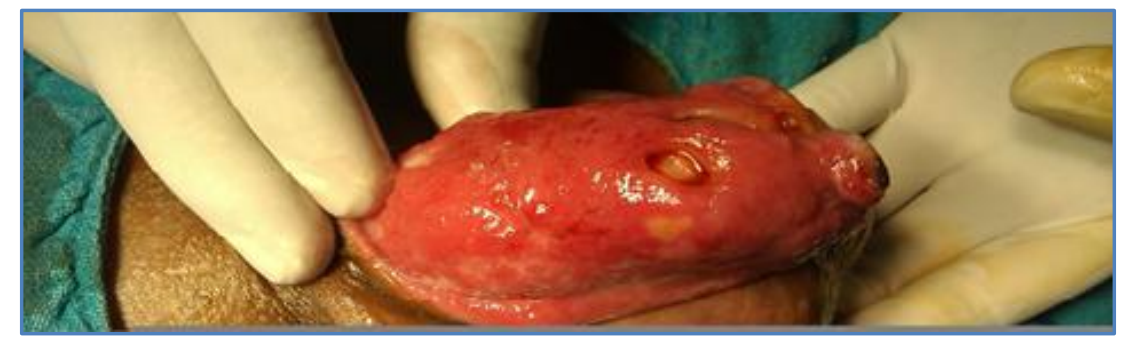

Figure 1

Emergency debridement of the gangrenous penile skin done and the inflammatory fluid was drained. After repeated debridement and dressings the bed was finally healthy (FIGURE -1), and an unexpanded, meshed, split-thickness skin graft was performed (FIGURE -2), by placing the graft junction on the ventral surface of the penis. ${ }^{5}$ The graft dressing was changed on the fourth and sixth postoperative days (FIGURE -3), and it revealed a 100\% take of the graft. The postoperative period was uneventful. Pt has come for follow up on $2^{\text {nd }}$ month $3^{\text {rd }}$ month and 6 month post operatively, his erectile function preserved well.

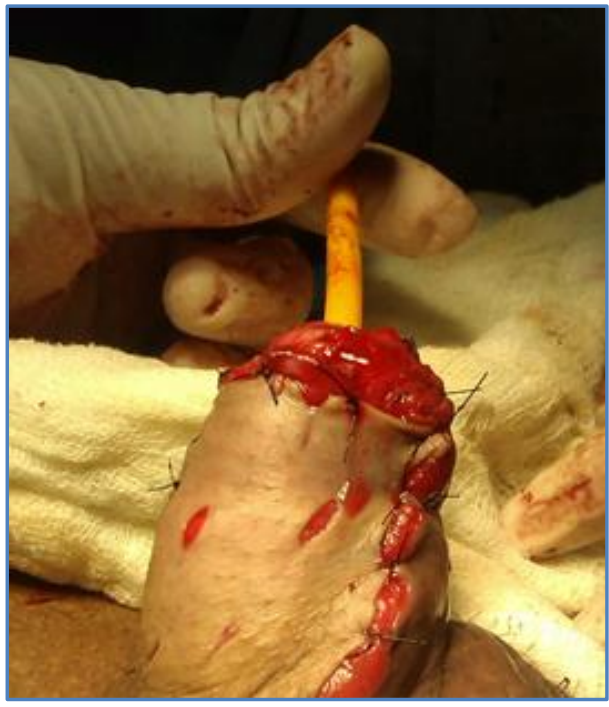

Figure 2: Inta operative picture showing split skin graft placed over penile shaft 

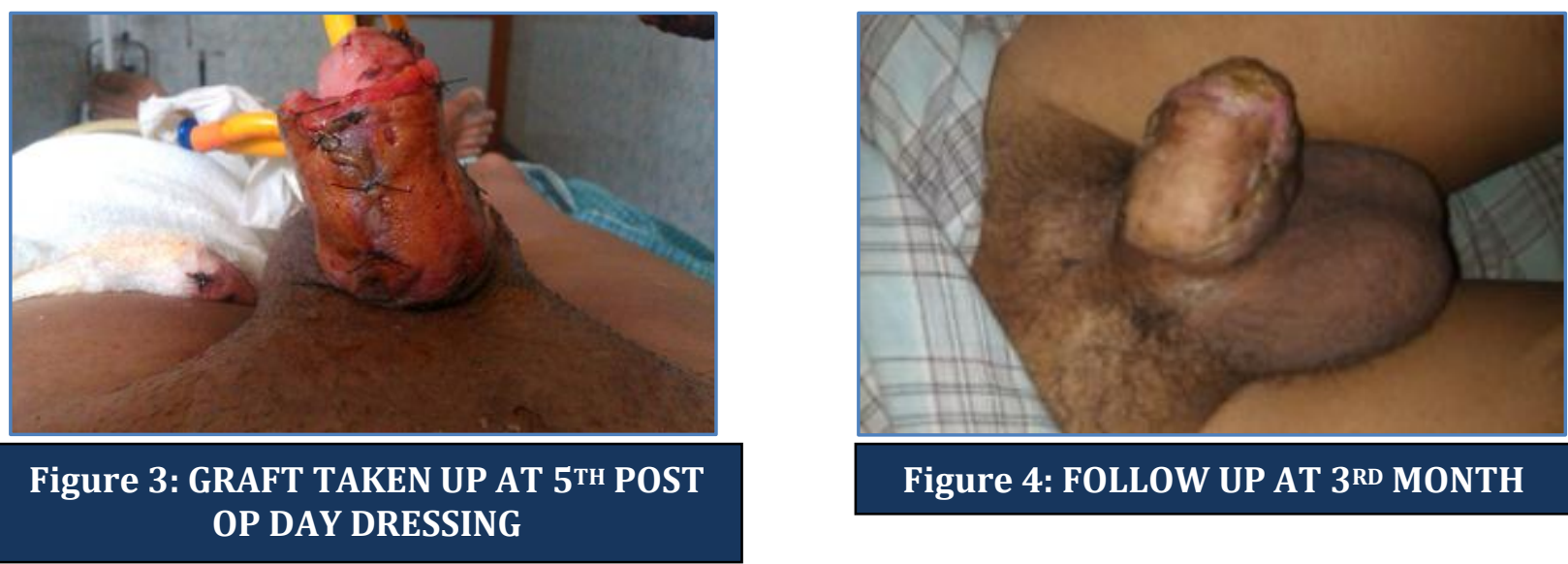

Figure 4: FOLLOW UP AT 3 ${ }^{\mathrm{RD}}$ MONTH

DISCUSSION: Fournier's gangrene is a rare, fulminant, and usually localized disease of the scrotum and penis, with occasional extension up to the abdominal wall. The usual organism is an anaerobic streptococcus synergistic with other organisms like enterobacteria species, staphylococcal species, anerobic organisms and fungi. Our case was unusual in that only the penis was involved, without any involvement of the scrotum or abdominal wall. Early therapy is the key, including hospitalization, debridement of the entire shaft of the penis distal to the devastated area without excising the normal skin, parenteral broad-spectrum antibiotics and skin grafting. Only few cases of Fournier's gangrene of the penis have been reported.6-9 The following are the pathognomonic findings on the pathological evaluation of the involved tissue:

a. Necrosis of the superficial and deep fascial planes

b. Fibrinoid coagulation of the nutrient arterioles

- Polymorphonuclear cell infiltration

- Microorganisms identified within the involved tissues

- Air in the perineal tissues

Infection represents an imbalance in host immunity, which is frequently compromised by one or more of the above-mentioned co-morbid systemic processes and the virulence of the causative microorganisms. The etiological factors allow the portal for entry of the microorganism into the perineum. The compromised immunity provides a favorable environment to initiate the infection and the virulence of the microorganism promotes the rapid spread of the disease.8.Microorganism virulence results from the production of toxins or enzymes that create an environment conducive to rapid microbial multiplication.

In a 1924 series of Chinese men with necrotizing infections, Meleney reported that the predominant organisms recovered from the cultures were the streptococcal species. Meleney attributed the necrotizing infection to this sole organism; however, subsequent clinical series have emphasized the multi-organism nature of most cases of necrotizing infection, including Fournier's gangrene.

At present, recovering only streptococcal species is unusual; rather, streptococcal organisms are cultured along with as many as five other organisms. The following are the common causative microorganisms: streptococcal species, staphylococcal species, enterobacteriaceae species, anaerobic organisms and fungi. Most authorities believe the polymicrobial nature of this disease is necessary to create the synergy of enzyme production that promotes rapid multiplication and spread of the infection. 
For example, one microorganism might produce the enzymes necessary to cause coagulation of the nutrient vessels. Thrombosis of these nutrient vessels reduces local blood supply; thus, the tissue oxygen tension falls. The resultant tissue hypoxia allows growth of facultative anaerobes and microaerophilic organisms. The latter microorganisms, in turn, may produce enzymes (e.g., lecithinase, collagenase), which lead to the digestion of fascial barriers, thus fueling the rapid extension of the infection.

Fascial necrosis and digestion are the hallmarks of this disease process; this is important to appreciate because it provides the surgeon with a clinical marker of the extent of tissue involvement. Specifically, if the fascial plane can be separated easily from the surrounding tissue by blunt dissection, it is quite likely to be involved with the ischemic-infectious process; therefore, any such dissected tissue should be excised. Far-advanced or fulminant disease can spread from the fascial envelopment of the genitalia throughout the perineum, along the torso, and occasionally, into the thighs.

The hallmark of Fournier's gangrene is intense pain and tenderness in the genitalia. ${ }^{8}$ The clinical course usually progresses through the following phases:

a. Prodromal symptoms of fever and lethargy, which may be present for two to seven days

b. Intense genital pain and tenderness that is usually associated with edema of the overlying skin

c. Increasing genital pain and tenderness with progressive erythema of the overlying skin

d. Dusky appearance of the overlying skin; subcutaneous crepitation

e. Obvious gangrene of a portion of the genitalia; purulent drainage from the wounds

The systemic effects of this process vary from local tenderness with no toxicity to florid septic shock. In general, the greater the degree of necrosis the more profound the systemic effects. The typical patient would be an elderly male in his sixth or seventh decade of life with comorbid diseases; females are not immune to this disease, but are affected less frequently.

The characteristic histological finding that most commonly indicates Fournier's disease is fibrinoid thrombosis of the nutrient vessels that supply the superficial and deep fascia. A frequent occurrence is a widespread necrosis of the fascia with acute inflammatory cell infiltration, necrotic debris and frequent demonstration of causative microorganisms within the tissues. This extensive inflammatory process is often present deep in the intact skin, which is often minimally involved with the inflammatory process until late in the disease.

Treatment also involves the institution of broad-spectrum antibiotic therapy. The antibiotic spectrum should cover staphylococci, streptococci, the Enterobacteriaceae family of organisms and anaerobes. A reasonable empiric regimen might consist of ciprofloxacin and clindamycin. Clindamycin is particularly useful in the treatment of necrotizing soft tissue infections, due to its gram-positive and anaerobic spectrum of activity. Clindamycin has been shown, in animal models of streptococcal infection, to have superior response rates compared to penicillin or erythromycin, even though the treatment is delayed.10,11

If the initial tissue stains show fungi, an empiric antifungal agent such as amphotericin B is added. In cases associated with the sepsis syndrome, therapy with intravenous immunoglobulin (IVIG), which is thought to neutralize superantigens such as the streptotoxins (A, B) believed to mitigate the exaggerated cytokine response, has been shown to be a good adjuvant to appropriate antibiotic coverage and complete surgical debridement. ${ }^{12}$ 
Only few cases of Fournier's gangrene of the penis have been reported so far. This case is reported because of its rarity.

\section{REFERENCES:}

1. Asci R, Sarikaya S, Buyukalpelli R, Yilmaz AF, Yildiz S. Fournier's gangrene: Risk assessment and enzymatic debridement with lyophilized collagenase application. Eur Urol. 1998; 34: 411-8.

2. Ayumba BR, Magoha GA. Epidemiological aspects of Fournier's gangrene at Kenyatta National Hospital, Nairobi. East Afr Med J. 1998; 75: 586-9.

3. Ayumba BR, Magoha GA. Management of Fournier's gangrene at the Kenyatta National Hospital, Nairobi. East Afr Med J. 1998; 75: 370.

4. Basoglu M, Gul O, Yildirgan I, Balik AA, Ozbey I, Oren D. Fournier's gangrene: Review of fifteen cases. Am Surg. 1997; 63: 1019-21.

5. Black PC, Friedrich JB, Engrav LH, Wessells H. Meshed unexpanded split-thickness skin grafting for reconstruction of penile skin loss. J Urol. 2004; 172 : 976-9.

6. Bernstein SM, Celano T, Sibulkin D. Fournier's gangrene of penis. South Med J. 1976; 69: 1242-4

7. Schneider PR, Russell RC, Zook EG. Fournier's gangrene of penis: A report of two cases. Ann Plast surg. 1986; 17: 87-90.

8. Yumura Y, Chiba K, Saito K, Hirokawa M. Fournier's gangrene of penis in a patient with malignant lymphoma: A case report. Hinyokika Kiyo. 2000; 46: 735-7.

9. Tauro F, Roshan M, Satish BS, Ravikrishnan J, Leo M. Fournier's gangrene of the penis. Indian J Plast Surg. 2005; 38: 154-6.

10. Efem SE. The features and aetiology of Fournier's gangrene. Postgrad Med J. 1994; 70: 568-71.

11. Frydenberg M. Penile gangrene: A separate entity from Fournier's syndrome? Br J Urol.1998; 61: 523-3.

12. Panagea S, Perry JD, Gould FK. Should clindamycin be used as treatment of patients with infections caused by erythromycin-resistant staphylococci? J Antimicrob Chemother. 1999; 44: 581-2.

\section{AUTHORS:}

1. Nagraj Mitra

2. Somshekar Solpure

\section{PARTICULARS OF CONTRIBUTORS}

1. Senior Resident, Department of Surgery, BRIMS, Bidar, Karnataka.

2. Junior Resident, Department of Surgery, BRIMS, Bidar, Karnataka.

\section{NAME ADDRESS EMAIL ID OF THE} CORRESPONDING AUTHOR:

Dr. Nagraj Mitra, Mitra Surgicare, Opposite Sanjay Indane Gas, KHB Colony, Bidar.

Email: nagaraj.mitra@gmail.com

Date of Submission: 02/04/2014. Date of Peer Review: 03/04/2014. Date of Acceptance: 23/04/2014. Date of Publishing: 09/05/2014. 